\title{
TAŞIYICI DUVAR UZUNLUKLARI DEPREM YÖNETMELIĞİ KURALLARINA UYGUN OLMAYAN DONATISIZ YIĞMA BİR YAPININ DENEYSEL OLARAK İNCELENMESİ
}

\author{
${ }^{1}$ Oktay Musa KAYIRGA, ${ }^{2}$ Fatih ALTUN \\ ${ }^{1}$ Erciyes Üniversitesi, Yapı İşleri ve Teknik Daire Başkanlığı, KAYSERİ \\ ²Erciyes Üniversitesi, Mühendislik Fakültesi, İnşaat Mühendisliği Bölümü, KAYSERI \\ 10kayirga@erciyes.edu.tr, 2faltun@erciyes.edu.tr
}

(Geliş/Received: 06.11.2017; Kabul/Accepted in Revised Form: 15.03.2018)

\begin{abstract}
ÖZ: Bu çalışmada, kapı ve pencere boşlukları nedeniyle taşıyıcı duvar uzunluğu deprem yönetmeliği kurallarına uygun olmayan $3 \times 3 \times 3$ m boyutlarında, tek katlı, tam (1:1) ölçekli donatısız yığma yapı, döngüsel yük etkisi altında deneysel olarak incelenmiştir. Döngüsel yük, yükleme duvarına monte edilen hidrolik yükleme düzeneği vasıtasıyla uygulanmış ve yük etkisi altında meydana gelen hasarlar yapı üzerine işaretlemiştir. Deplasman değerleri yedi adet deplasman ölçer ve veri kayıt sistemi ile kayıt altına alınmıştır. Elde edilen veriler değerlendirildiğinde, yığma yapı maksimum yük etkisinin \% 75 'ine kadar yaklaşık olarak doğrusal davranış gösterdiği ve bu döngülerde kılcal çatlaklar dışında hasar meydana gelmediği görülmüştür. Bu yük seviyesinden sonra, yapının açılıp kapanan çatlaklarla enerji tüketmeye devam ettiği ve 0,013 göreli kat ötelenme oranında göçme konumuna ulaştığ belirlenmiştir. Sonuç olarak, taşıyıcı duvar uzunluğunun hasara sebebiyet veren önemli bir etken olduğu ve yönetmelik kurallarına hassasiyetle uyulması gerektiği değerlendirilmiştir.
\end{abstract}

Anahtar Kelimeler: Donatısız yığma yapı, Döngüsel yük etkisi, Hasar, Taşıyıcı duvar uzunluğu, Experimental Investigation of Unreinforced Masonry Building Having Insufficient Loadbearing Wall
Lenght According to Turkish Earthquake Code Rules

\begin{abstract}
In this study, 3×3x3 m sized, single-story, full-scale (1:1) unreinforced masonry building having insufficient loadbearing-wall length because of window and door openings according to Turkish earthquake code rules was investigated experimentally under the cyclic load effect. Cyclic load was carried out via hydraulic load-jack mounted on reaction wall, and the damages occurred under the influence of cyclic load were marked on the building. The displacement values were recorded by seven displacement transducers and data recording system. When the obtained values were evaluated, it was observed that the building behaved approximately linear to $75 \%$ of maximum load, and damage did not occur in these cycles except a few capillary cracks. After this load level, it was determined that the building dissipated energy with opened-closed cracks, and bearing capacity reached ultimate capacity about 0,013 relative storey drift rate. As a result, it is evaluated that loadbearing-wall length is the important factor for cause of damage, and it is necessary to observe the code rules meticulously.
\end{abstract}

Key Words: Unreinforced masonry building, Cyclic load effect, Damage, Loadbearing-wall length,

\section{GİRIŞ (INTRODUCTION)}

Donatısız yığma yapılar, taşıyıcı sistemi doğal taşların veya tuğla, beton briket, gazbeton, kireç kumtaşı vb. gibi yapay taşların bağlayıcı bir harç ile örülmesi suretiyle oluşturulan bina türleridir. 
Günümüzde, yapımı geçmişe oranla giderek azalsa da, inşa edilmiş pek çok yığma yapı bulunmaktadır. Özellikle kırsal kesimlerde yoğun olarak bulunan yığma yapılar ülkemiz yapı envanterinin \% 51 gibi büyük bir bölümünü oluşturmaktadır (DİE,2000). Genellikle yöresel malzemeler kullanılarak geleneksel olarak inşa edilen bu tür yapılarda deprem etkisi altında ağır hasarlar meydana gelebilmektedir. Bu durum can ve mal kaybına sebep olabilmektedir.

Dünyanın en etkin deprem kuşaklarından birinin üzerinde yer alan ülkemiz yüzölçümünün \% 92'si deprem bölgeleri içerisinde yer almakta olup, son idari yapılanmaya göre nüfusunun \% 98,8'i bu bölgeler içerisinde yaşamaktadır (Birinci ve Haciefendioğlu, 2015). Aktif deprem kuşağında olan ülkemizde yapı envanterinin önemli bir bölümünü oluşturan yı̆̆ma yapıların deprem davranışının bilinmesi önem arz etmektedir.

Yığma yapı davranışı üzerine pek çok çalışma mevcuttur. Konu ile ilgili olarak deneysel çalışmalar (Altun ve Kayırga, 2014; Lourenço ve diğ., 2013; Shahzada ve diğ., 2012; Bothara ve diğ., 2010); duvar boşluk durumlarının incelendiği çalışmalar (Altun ve Kayırga, 2015; Ural, 2005) ve deprem hasarları üzerinden yapı davranışının incelendiği çalışmalar (Doğangün ve Ural, 2008; Arun, 2005) olarak verilebilir.

Çalışmada, yukarıda belirtilen çalışmalardan farklı olarak, taşıyıcı duvar uzunluğu Deprem Bölgelerinde Yapılacak Binalar Hakkında Yönetmelik (DBYBHY, 2007) 5. Bölüm kurallarına uygun olmayan yığma bir yapının, döngüsel yük etkisi altında davranışı ve hasar gelişimi incelenmiştir. Yönetmelikte, yığma yapıların bina köşesine en yakın pencere ve kapı arasında kalan taşıyıcı duvar uzunluğu, kapı ve pencere arasında kalan duvar uzunluğu, boşluk uzunluklarının toplamı ve toplam duvar uzunluğuna olan oranı depreme dayanıklı tasarım kuralları arasında yer almaktadır. Bu amaçla tam (1:1) ölçekli olarak inşa edilen yığma yapıya, reaksiyon duvarına monte edilen hidrolik kriko vasıtasıyla döngüsel yatay yük etki ettirilmiştir. Her bir döngüde meydana gelen hasarlar yapı üzerinde işaretlenmiş ve deplasman ölçerlerden elde edilen değerler veri toplama sistemi vasıtasıyla kayıt altına alınmıştır.

Deney sonucunda, yapıda karakteristik çapraz çatlak oluşumu, duvar rijitlik farkına bağlı burulma hasarı ve özellikle taşıyıcı duvar boşluğu fazla olan duvarda büyük oranda hasar meydana geldiği tespit edilmiş ve sonuçlar değerlendirilmiştir.

\section{MATERYAL (MATERIAL)}

Deneysel çalışmada, yığma yapı duvar malzemesi olarak kireç kumtaşı kargir birimler sınıfı içerisinde yer alan ve içerisinde yüksek oranda silis bulunduran pomza taşı ile kirecin birleşiminden oluşan yığma yapı malzemesi kullanılmıştır. Malzemeye ilişkin üretici firma tarafından verilen fiziksel ve mekanik değerler Çizelge 1 'de verilmiştir.

Çizelge 1. Duvar malzemesinin fiziksel ve mekanik değerleri

\begin{tabular}{|l|l|}
\hline \multicolumn{2}{|c|}{ Table 1. Mechanical and physical values of masonry unit } \\
\hline Obzellikler & Değerler \\
\hline Ebat & $190 \times 190 \times 375 \mathrm{~mm}$ \\
Ortalama Basınç Mukavemeti & $5 \sim 7 \mathrm{MPa}$ \\
Net Kuru Birim Hacim Kütlesi & $1100 \sim 1300 \mathrm{~kg} / \mathrm{m}^{3}$ \\
Ağırlık & $12 \mathrm{~kg} /$ adet $( \pm \% 10)$ \\
\hline
\end{tabular}

Duvar örgüsünde, duvar malzemesi üreticisi tarafından $25 \mathrm{~kg}{ }^{\prime} \mathrm{llk}$ hazır torbalar halinde üretilen çimento esaslı yapıştırma harcı kullanılmıştır. Bir torba yapıştırma harcı 7 8 litre su ile topaklanma kalmayana kadar karıştırılarak kullanıma hazır hale getirilmiştir. Hazırlanan harç yaklaşık 10 dakika kadar bekletilerek uygulanmıştır. Uygulanan yüzeyin temiz ve nemli olmasına ve hazırlanan karışımın 3 saat içerisinde tüketilmesine kullanma talimatı gereği özen gösterilmiştir. 
Deneysel çalışmada, yüklerin duvarlara rijitlikleri oranında dağıtılması amacıyla, betonarme döşeme ve hatıl sistemi oluşturulmuştur. Döşeme ve hatıl imalatında C25 sınıfı beton ve S420 nervürlü donatı kullanılmıştır.

\section{METOD (METHOD)}

Deprem Bölgelerinde Yapılacak Binalar Hakkında Yönetmeliğin (DBYBHY-2007) taşıyıı duvar boşlukları başlıklı 5.4.6 maddesinde:

- Bina köşesine en yakın pencere ya da kapı ile bina köşesi arasında bırakılacak dolu duvar parçasının plandaki uzunluğu birinci ve ikinci derece deprem bölgelerinde1.50 m'den, üçüncü ve dördüncü derece deprem bölgelerinde $1.0 \mathrm{~m}$ 'den az olamaz,

- Bina köşeleri dışında pencere ve kapı boşlukları arasında kalan dolu duvar parçalarının plandaki uzunluğu birinci ve ikinci derece deprem bölgelerinde $1.0 \mathrm{~m}$ 'den, üçüncü ve dördüncü derece deprem bölgelerinde $0.80 \mathrm{~m}$ 'den az olamaz,

denilmektedir. Deneysel araştırma amacıyla, kapı ve pencere boşluklarının bina köşesine olan uzaklıkları ile pencere boşlukları arası uzunluğu yukarıda belirtilen kriterlere uymayan yığma yapı planı tasarlanmıştır. Tasarlanan mimari planda, bina köşesinden en yakın kapı boşluğuna kadar olan dolu duvar uzunluğu $0,94 \mathrm{~m}$; bina köşesinden pencere boşluğuna kadar olan dolu duvar uzunluğu 0,57 m'dir. Yine, planda pencere boşlukları arasında kalan dolu duvar parçası uzunluğu 0,56 $\mathrm{m}$ olarak alınmıştır. Tasarlanan yapıya ait plan ve kesit Şekil 1'de verilmiştir.

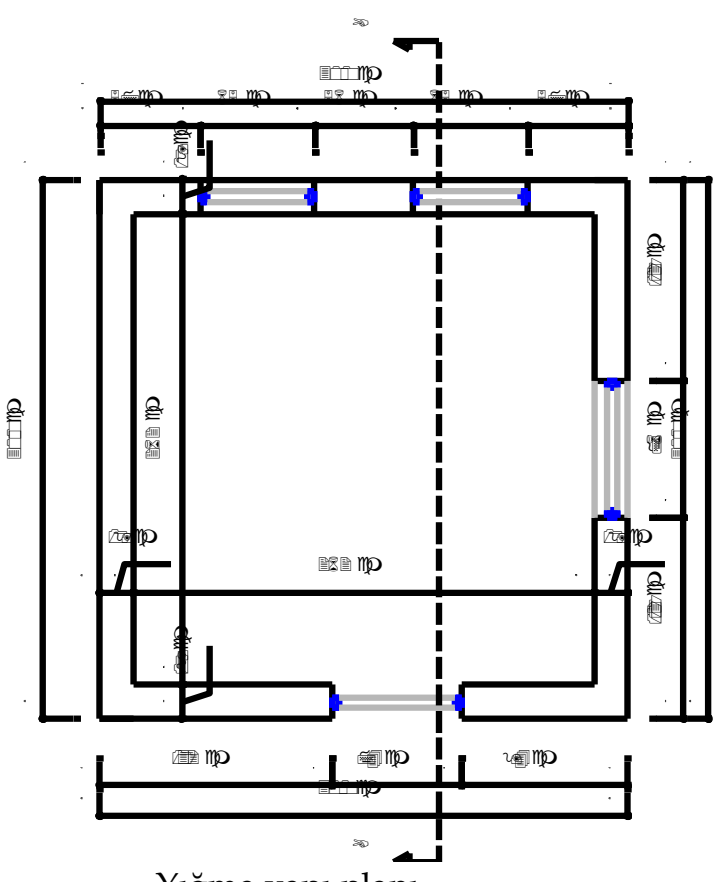

Yı̆̆ma yapı planı

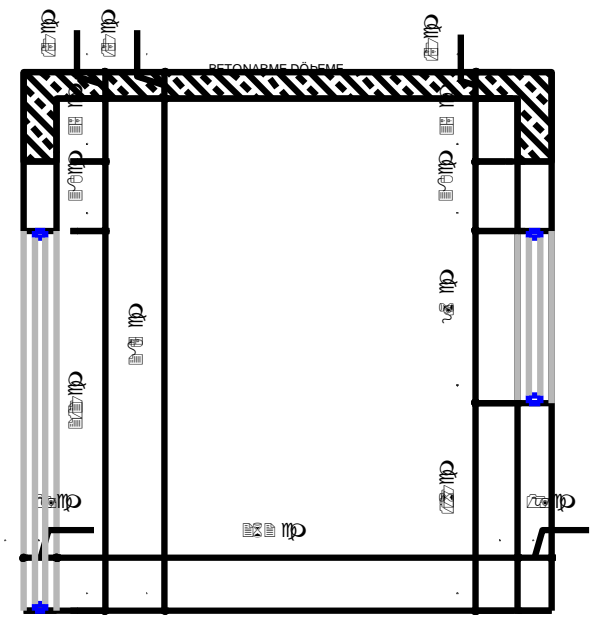

A-A kesiti

Şekil 1. Yı̆̆ma yapı planı ve en kesiti

Figure 1. Plan and cross-section of Masonry building

Döngüsel yük etkisi, reaksiyon duvarına monte edilen hidrolik kriko vasıtasıyla uygulanmıştır. Hidrolik kriko doğrultusunda uygulanan yük itme (+) ve çekme (-) yönü olarak adlandırılmıştır. Yük etkisi altında meydana gelen deplasmanlar için yedi adet deplasman ölçer kullanılmıştır. Dört adet deplasman ölçer uygulanan yük doğrultusunda, iki tanesi meydana gelebilecek dönme etkisinin ölçülmesi için bina çapraz köşelerine, bir adet deplasman ölçer ise kontrol amaçlı bina arka köşesine monte edilmiştir. Deney düzeneği Şekil 2' de verilmiştir. 

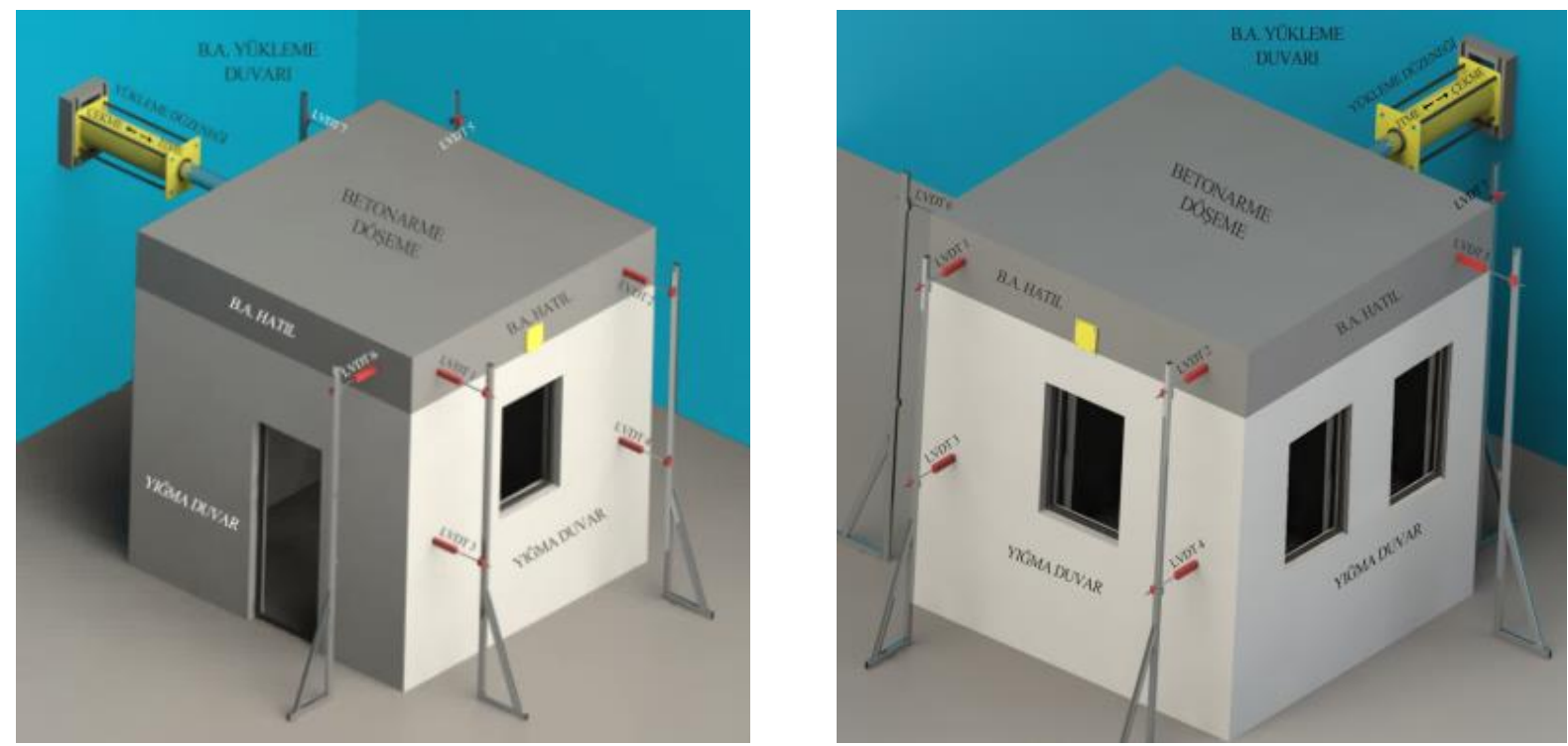

Şekil 2. Deney düzeneği

Figure 2. Experimental Setup

\section{BULGULAR (RESULTS)}

Deneysel çalışmaya itme ve çekme yönünde $5 \mathrm{kN}$ yük etkisi ile başlanmış ve yük etkisi her bir döngüde $5 \mathrm{kN}$ artırılmıştır. Beşinci döngüye kadar yapıda hasar gözlemlenmemiştir. Beşinci döngüden itibaren yapıda kılcal çatlak düzeyinde hasar gelişimi başlamıştır. İlk yedi döngüye ait yük ve meydana gelen tepe deplasman ortalama değerleri Çizelge 2 ' de verilmiştir.

Çizelge 2. İlk yedi döngüye ait yük-deplasman değerleri Table 2. Load-Displacement values belong to first seven cycles

\begin{tabular}{|c|cccc|}
\hline $\begin{array}{c}\text { Döngü } \\
\text { No. }\end{array}$ & $\begin{array}{c}\text { Yük } \\
\text { İtme Yönü } \\
\mathbf{( + )} \\
\mathbf{( k N )}\end{array}$ & $\begin{array}{c}\text { Yük } \\
\text { Çekme } \\
\text { Yönü (-) } \\
\mathbf{( k N )}\end{array}$ & $\begin{array}{c}\text { Ortalama } \\
\text { Deplasman } \\
\text { İtme Yönü (+) } \\
(\mathbf{m m})\end{array}$ & $\begin{array}{c}\text { Ortalama } \\
\text { Deplasman } \\
\text { Çekme Yönü(-) } \\
\text { (mm) }\end{array}$ \\
\hline 1 & 5,008 & 5,104 & 0,081 & 0,077 \\
2 & 10,126 & 10,031 & 0,185 & 0,168 \\
3 & 15,243 & 15,039 & 0,300 & 0,282 \\
4 & 20,139 & 20,115 & 0,435 & 0,428 \\
5 & 25,134 & 25,165 & 0,633 & 0,646 \\
6 & 30,167 & 30,092 & 0,929 & 0,992 \\
7 & 35,157 & 35,127 & 1,519 & 1,708 \\
\hline
\end{tabular}

Yedinci döngüde yaklaşık 35 kN yük etkisi ile histeresiz eğrisinde karakteristik değişiklik meydana geldiği gözlemlenmiştir. Bu aşamada, doğrusal olduğu kabul edilen yük deplasman grafiğinin doğrusallıktan uzaklaştığı değerlendirilmiştir. Meydana gelen bu değişiklik sonucunda deneysel çalışmanın deplasman kontrollü olarak devam etmesi kararlaştırılmış ve bu aşamadan sonra deplasman kontrollü yüklemeler yapılmıştır. Histeresiz eğrisinde meydana gelen değişimle birlikte duvar malzemesi harç birleşiminde çatlak oluşumu da gözlemlenmiştir. Duvar malzemesi ile harç arasında başlayan çatlaklar 9. Döngüden itibaren basamaklı karakteristik çapraz çatlak haline dönüşmeye başlamıştır. Yükleme sonucunda gelişen hasarlara ilişkin fotoğraflar Şekil 3’de verilmiştir. 

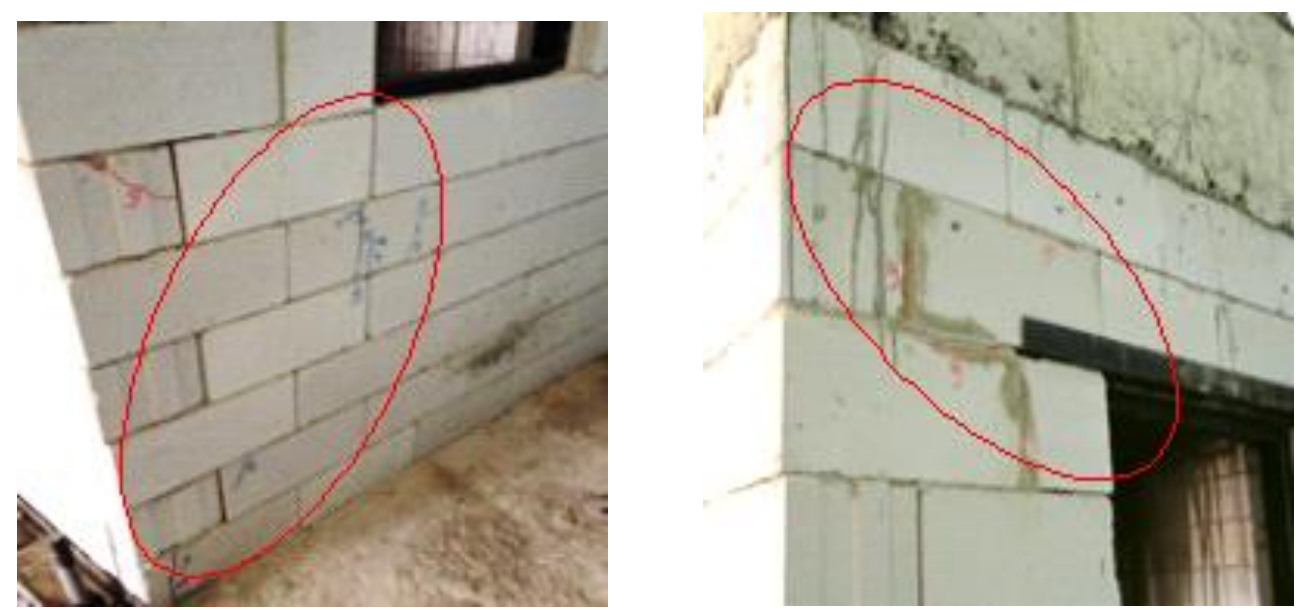

Şekil 3. İlk karakteristik hasarlar

Figure 3. First characteristic cracks

Artan yükleme etkisiyle, bu aşamadan itibaren kapı ve pencere boşluk köşelerinden yapı köşelerine doğru basamaklı çapraz çatlak gelişimleri artarak devam etmiş, hasar gelişimi ile yapının yük taşıma kapasitesi, itme ve çekme yönünde $40 \mathrm{kN}$ seviyesine kadar ulaşmıştır. Belirtilen aşamaya ilişkin yapının çeşitli bölgelerinden alınan fotoğraflar Şekil 4'de verilmiştir.
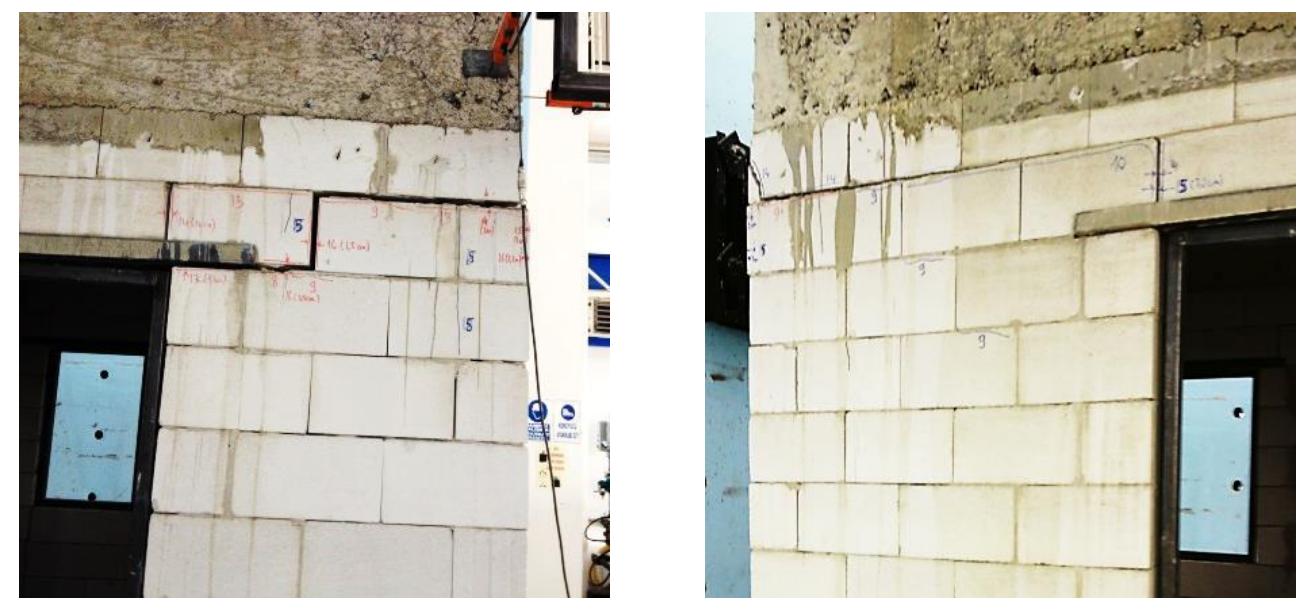

Şekil 4. Maksimum yük etkisi altında hasar durumları

Figure 4. The damages under the maximum load effect

Kapı ve pencere boşluklarına bağlı rijitlik farkı nedeniyle uygulanan yük etkisi doğrultusundaki duvarda burulma hasarları gözlemlenmiştir. Burulma etkisinin incelenmesi amacıyla yapı çapraz köşelerine yerleştirilen deplasman ölçerlerden alınan deplasman değerleri Çizelge 3'de, hasara ilişkin örnek fotoğraflar Şekil 5'de verilmiştir.

Çizelge 3. Burulma hasarı deplasman değerleri

\begin{tabular}{|c|c|c|c|c|}
\hline \multirow[b]{2}{*}{ Döngü No } & \multicolumn{2}{|c|}{ İtme Yönü (+) } & \multicolumn{2}{|c|}{ Çekme Yönü(-) } \\
\hline & $\begin{array}{l}\text { Burulma (Sağ) } \\
(\mathrm{mm})\end{array}$ & $\begin{array}{l}\text { Burulma } \\
\text { (Sol) (mm) }\end{array}$ & $\begin{array}{c}\text { Burulma (Sağ) } \\
(\mathrm{mm})\end{array}$ & $\begin{array}{l}\text { Burulma } \\
\text { (Sol) }(\mathrm{mm})\end{array}$ \\
\hline 23. Döngü & $-5,87$ & $-9,38$ & $-8,55$ & $-16,82$ \\
\hline
\end{tabular}



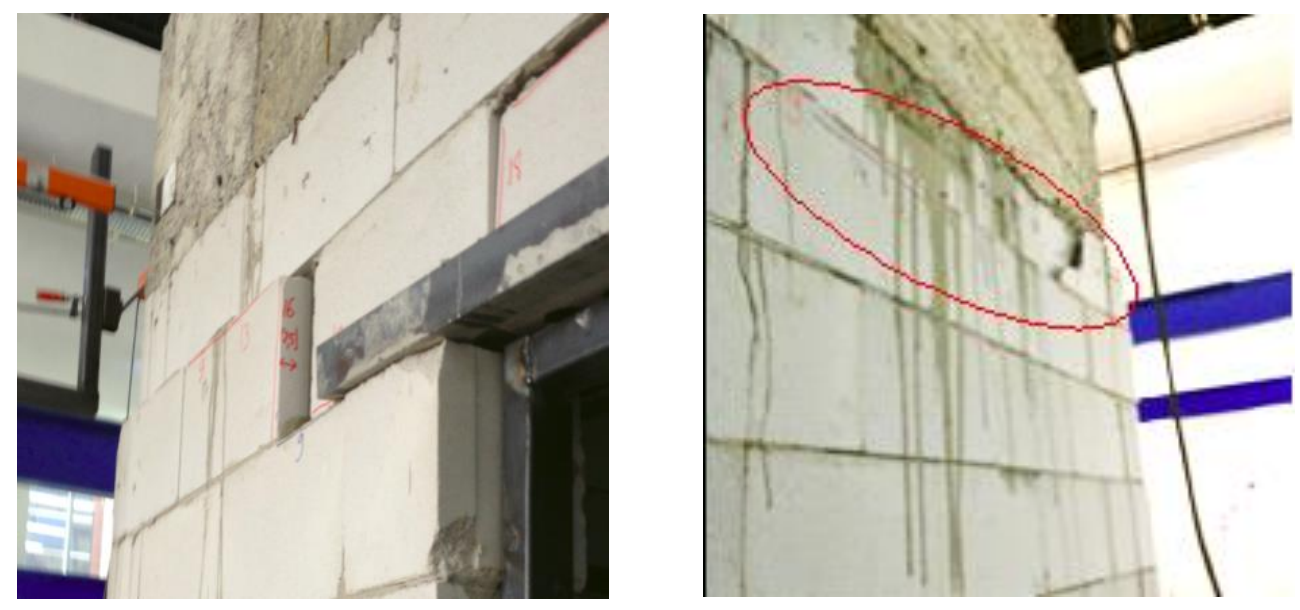

Şekil 5. Burulma hasarları

Figure 5. Twist damages

Devam eden döngülerde yük etkisi altında çatlak gelişimi artmış ve deney sonuna kadar çatlak gelişimi $35 \mathrm{~mm}$ mertebelerine ulaşmıştır. Yapı, her iki doğrultudaki yük etkisi altında meydana gelen çatlakların açlıp kapanması ile enerji tüketmeye devam etmiştir. Yirminci döngü itibariyle hasarlar kalıcı hale gelmeye başlamış, malzemede kopma ve dökülmeler meydana gelmiştir. Hasarlara ilişkin örnek fotoğraflar Şekil $6^{\prime}$ da verilmiştir.
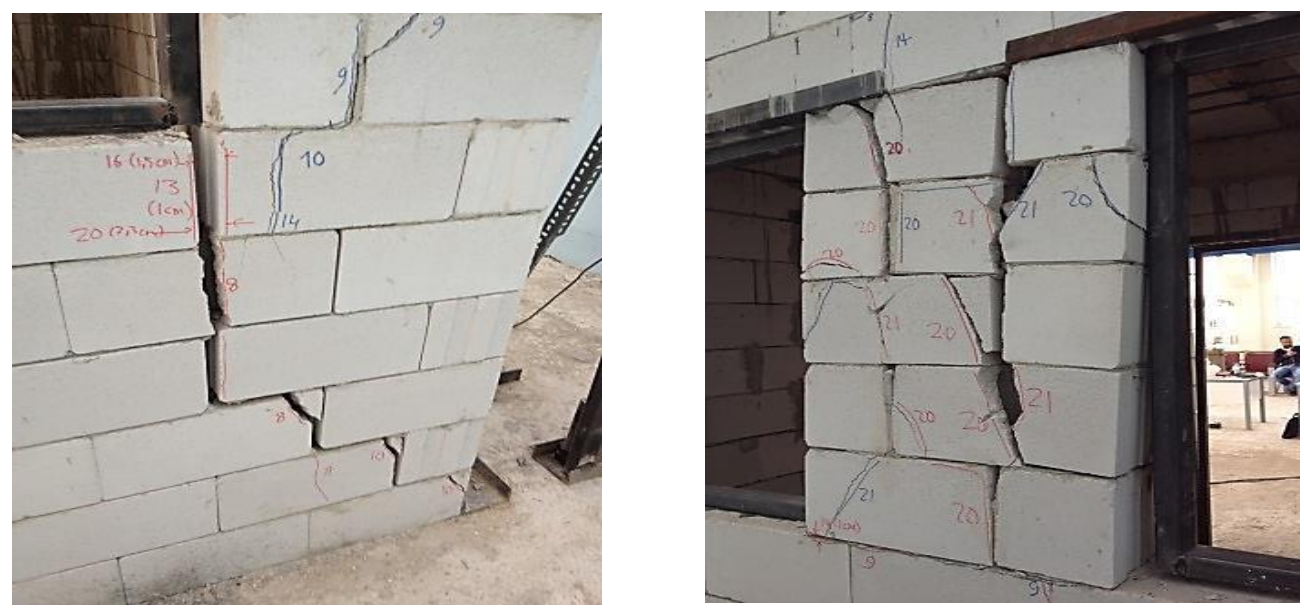

Şekil 6. Deney sonu itibariyle maksimum hasar durumları Figure 6. Maimum damages at the end of the experimental study

İlk yedi döngü sonrası uygulanan yük ve meydana gelen tepe deplasman ortalama değerleri Çizelge 4 'de verilmiştir. 
Çizelge 4. Yedinci döngü sonrası yük-deplasman değerleri Table 4. Load-Displacement values after first seven cycles

\begin{tabular}{|c|cccc|}
\hline \multicolumn{5}{|c}{ Table 4. Load-Displacement values after first seven cycles } \\
$\begin{array}{c}\text { Döngü } \\
\text { No. }\end{array}$ & $\begin{array}{c}\text { Yük } \\
\text { İtme Yönü } \\
\mathbf{( k N ) ( + )}\end{array}$ & $\begin{array}{c}\text { Yük } \\
\text { Çekme Yönü } \\
(\mathbf{k N ) ( - )}\end{array}$ & $\begin{array}{c}\text { Ortalama } \\
\text { Deplasman } \\
\text { İtme Yönü } \\
(\mathbf{m m})(+)\end{array}$ & $\begin{array}{c}\text { Ortalama } \\
\text { Deplasman } \\
\text { Çekme Yönü } \\
(\mathbf{m m})(-)\end{array}$ \\
\hline 8 & 37,542 & 34,367 & 3,751 & 3,741 \\
9 & 37,796 & 36,675 & 5,710 & 5,713 \\
10 & 38,686 & 37,313 & 7,710 & 7,719 \\
11 & 39,208 & 37,665 & 9,706 & 9,726 \\
12 & 40,013 & 38,507 & 11,718 & 11,722 \\
13 & 34,790 & 39,023 & 14,014 & 14,004 \\
14 & 34,522 & 39,118 & 16,002 & 16,009 \\
15 & 33,930 & 39,579 & 18,002 & 18,002 \\
16 & 33,789 & 39,199 & 20,000 & 20,009 \\
17 & 33,677 & 39,172 & 22,002 & 22,025 \\
18 & 30,026 & 37,625 & 24,010 & 24,005 \\
19 & 27,545 & 37,760 & 26,018 & 26,002 \\
20 & 26,826 & 36,661 & 28,010 & 28,008 \\
21 & 27,925 & 37,000 & 30,003 & 30,036 \\
22 & 27,700 & 36,159 & 35,006 & 35,009 \\
23 & 27,164 & 35,833 & 40,001 & 40,001 \\
\hline
\end{tabular}

Döngüsel yük etkisi altında bilgisayar kayıt sistemi verileri ile elde edilen histeresiz eğrisi Şekil 7'de verilmiştir.

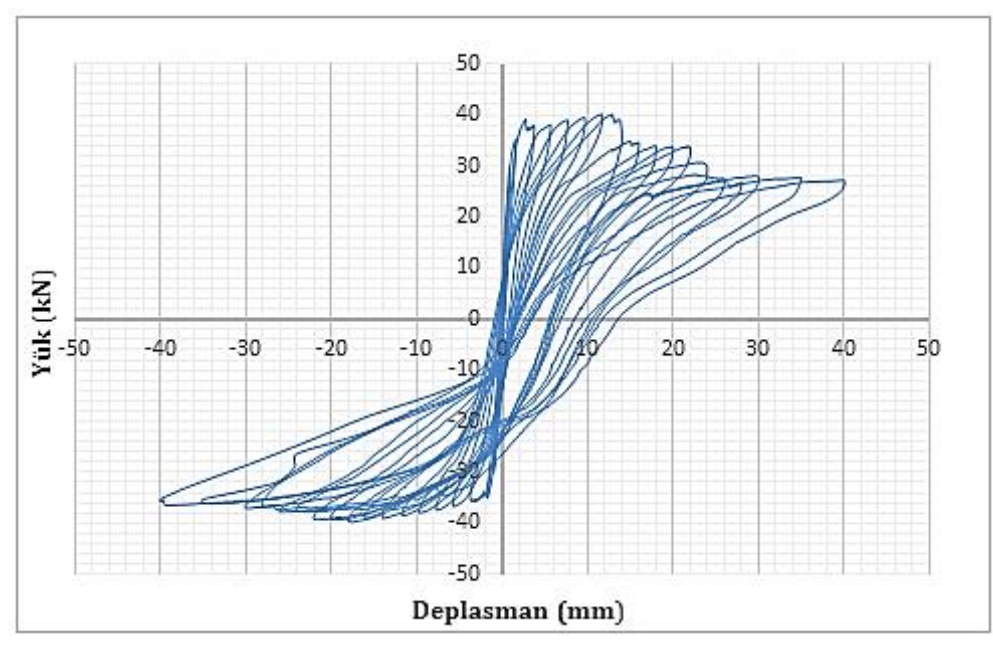

Şekil 7. Histeresiz grafiği

Figure 7. Hysteresis loop

Şekil 7 'de verilen histeresiz eğrilerinin tepe noktalarının birleştirilmesi ile oluşturulan itme ve çekme yönündeki zarf eğrisi Şekil 8'de verilmiştir. 


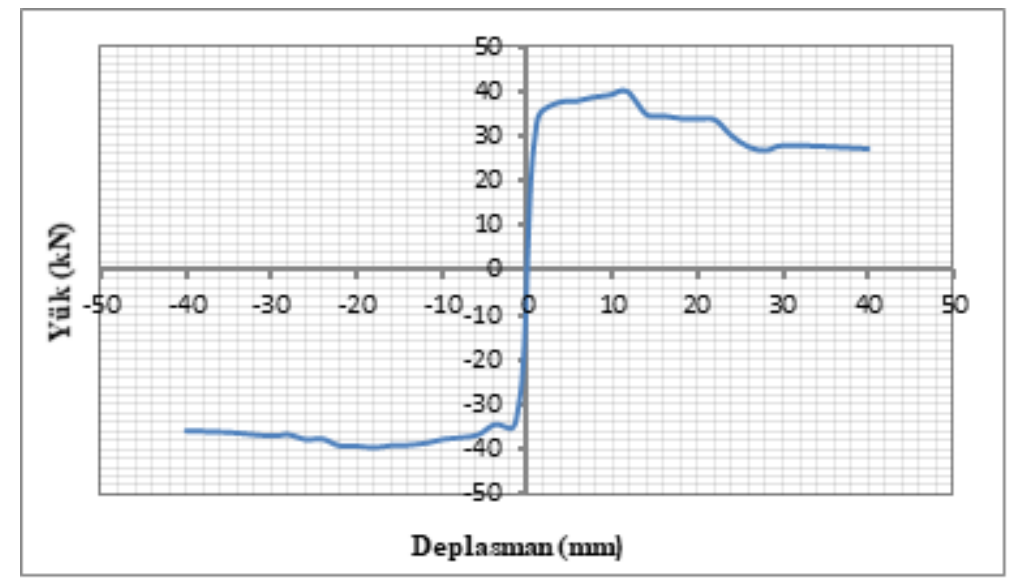

Şekil 8. Zarf eğrisi

Figure 8. Envelope curves

Döngüsel yük etkisi altında yığma yapı duvarlarında meydana gelen hasarları gösterir dağılım Şekil $9^{\prime}$ da verilmiştir.

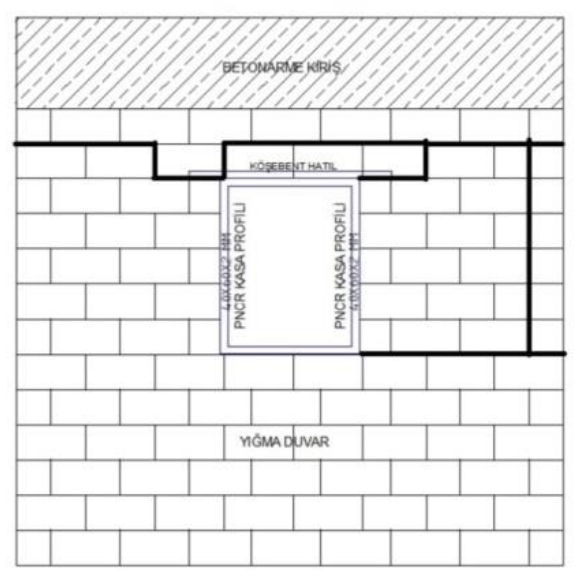

Ön Duvar

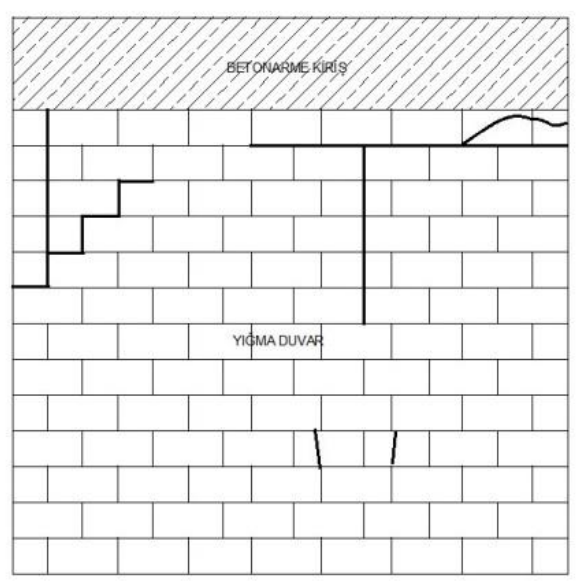

Arka Duvar

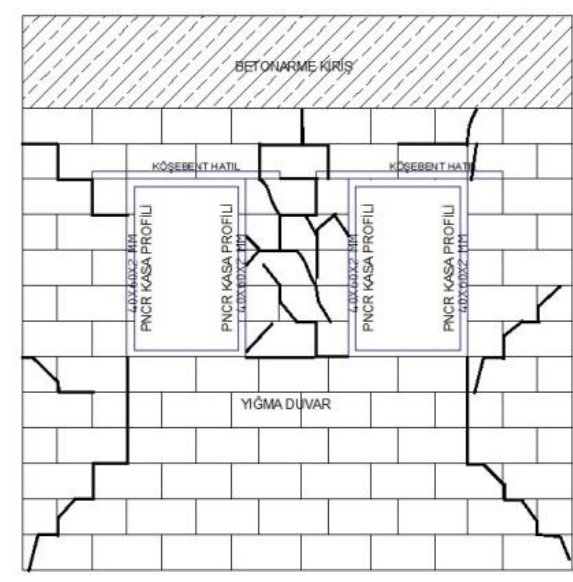

Sağ Yan Duvar

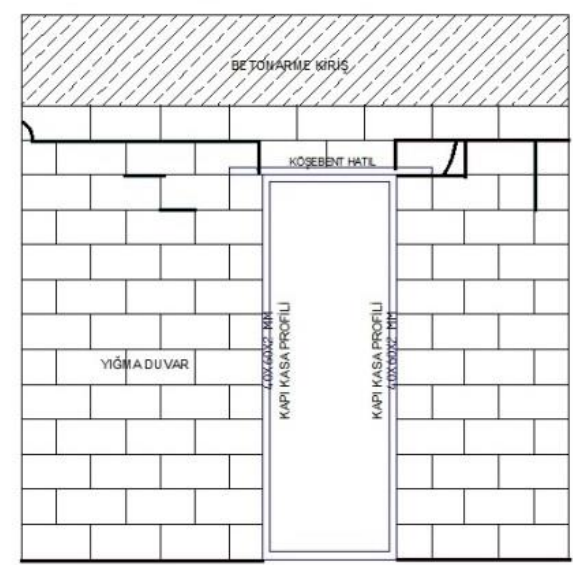

Sol Yan Duvar

Şekil 9. Yı̆̆ma yapı hasar dağılımı

Figure 9. Damage distrubition on the building sides 


\section{SONUÇLAR (CONCLUSIONS)}

Deneysel çalışma ile elde edilen histeresiz ve zarf eğrileri değerlendirildiğinde, yığma yapının maksimum yükün \%75'ine kadar olan yük değerlerinde yaklaşık doğrusal davranış gösterdiği, bu aşamalarda kılcal çatlaklar dışında hasar meydana gelmediği görülmüştür. Bu aşamadan sonra histeresiz eğrisinde değişiklik meydana gelmiş ve deplasman değerleri doğrusal kabulünden uzaklaşmıştır. Yapıda karakteristik hasar oluşumu başlamış, oluşan çatlaklar ile yapı enerji sönümlemeye devam etmiştir. Her iki yönde yaklaşık $40 \mathrm{kN}$ maksimum yük seviyesinden sonra yapının yük taşıma kapasitesi azalırken, yapı açılıp kapanan çatlaklar ile enerji sönümlenmeye devam etmiştir. Devam eden döngülerde yapı malzemelerinde kopma ve dökülmeler başlamış, göreli kat ötelenmesinin 0,013 seviyesine ulaştığı anda, yığma yapının göçme öncesi seviyeye ulaştığı kabulü ile deneysel çalışmaya son verilmiştir.

Yapıda meydana gelen hasar tipleri değerlendirildiğinde, uygulanan yük doğrultusundaki duvarlarda çatlakların karakteristik çapraz çatlak şeklinde meydana geldiği görülmüştür. Bu hasarlar, basamaklı şekilde, blok malzeme harç birleşim yüzeylerinde meydana gelmiş ve deney sonu itibariyle $35 \mathrm{~mm}$ mertebelerine ulaşmıştır. Yığma yapı sağ yan duvarında iki pencere arasında kalan duvar parçasının ise, kısa rijit eleman olarak çalıştı̆̆ 1 ve tersinir yük etkisi altında malzeme bazında en büyük hasarın bu bölgede olduğu tespit edilmiştir. Ön ve arka duvar hasarları yatay ve düşey yönlü olarak meydana gelmiştir. Duvar rijitlik farkları nedeniyle meydana gelen yer değiştirmelere bağlı olarak, yatay yönlü ve blok malzeme harç birleşim yüzeylerinde burulma hasarları meydana gelmiştir.

Sonuç olarak, yığma yapılarda kapı, pencere vb. amaçla bırakılan boşlukların sebebiyet verdiği yetersiz taşıyıcı duvar uzunluğu ve yapının diğer duvarları ile rijitlik farkı, yapıda hasar oluşumuna sebebiyet veren önemli bir etken olduğu, bırakılması gereken boşluklar için yönetmelik kurallarına hassasiyetle uyulması gerektiği değerlendirilmiştir.

\section{TEŞEKKÜR (ACKNOWLEDGEMENTS)}

Bu çalı̧̧ma; Erciyes Üniversitesi Bilimsel Araştırma Projeleri Birimi tarafından FDK-2014-5219 kodlu proje ile desteklenmiştir.

\section{KAYNAKLAR (REFERENCES)}

Altun F., Kayırga O.M., "Experimental Investigation of Masonry Structure Behaviour Under The Influence of Cyclic Loading", International Civil Engineering and Architecture Symposium for Academicians (ICESA), Antalya, Turkey, 17-21 May 2014.

Altun, F., Kayırga, O.M., "Experimental Investigation of Window and Door Opening Effect on Masonry Building Behavior Under The Cyclic Load", International Science and Technology Conference (ISTEC), St. Petersburg, Russia, 2-4 September 2015.

Arun, G., "Yığma Kargir Yapı Davranışı", Yığma Yapıların Deprem Güvenliğinin Arttırılması Çalıştayı (YDGA-2005), Orta Doğu Teknik Üniversitesi, Ankara, 17 Şubat 2005.

Birinci, F., Hacıefendioğlu, K., "Nüfus-İdari Yapı-Plan-Kentleşme-Yapılaşma Perspektifinden Türkiye'nin Deprem-Afet Riski Analizi ve Çözüm Önerileri, 3. Türkiye Deprem Mühendisliği ve Sismoloji Konferansı, Dokuz Eylül Üniversitesi, İzmir, 14-16 Ekim 2015.

Bothara, J. K., Dhakal, R. P., Mander, J. B., 2010, “Seismic Performance of An Unreinforced Masonry Building: An Experimental Investigation", Earthquake Engineering \& Structural Dynamics, Vol. 39 (1), pp. $45-68$

DBYBHY, 2007, Deprem Bölgelerinde Yapılacak Binalar Hakkında Yönetmelik, Bayındırlık ve İskan Bakanlığı, Ankara, $159 \mathrm{~s}$.

DİE, 2000, Bina Sayımı, T.C. Başbakanlık Devlet İstatistik Enstitüsü, Ankara, 473 s. 
Doğangün, A., Ural, A., "Seismic Performance of Masonry Buildings During Recent Earthquakes in Turkey", The 14 ${ }^{\text {th }}$ World Conference on Earthquake Engineering, Beijing, China, 12-17 October 2008.

Lourenço, P. B., Avilla, L., Vasconcelos, G., Alves, J. P., Mendes, N., Costa, A. C., 2013, “Experimental Investigation on The Seismic Performance of Masonry Buildings Using Shaking Table Test", Bull Earthquake Eng., Vol. 11, pp. 1157-1190

Shahzada, K., Khan, A. N., Elnashai, A. S., Ashraf, M., Javed, M., Naseer, A., Alam, B., 2012, "Experimental Seismic Performance Evaluation Brick Masonry Buildings", Earthquake Spectra (August 2012), Vol. 28 (3), pp. 1269-1290.

Ural, A., “Taşıyıcı Duvarlarda Farklı Boşluk Yapılandırılmasına Sahip Sarılmış Yığma Yapıların Deprem Davranışının İncelenmesi", Deprem Sempozyumu, Kocaeli, 23-25 Mart 2005. 